\title{
Influence of Socio-economic Status on Oral Health Knowledge, Attitude and Behavior of Pensioners in Port Harcourt, Rivers State
}

\author{
Braimoh Omoigberai Bashiru*, Alade Grace Oyenashia \\ Department of Preventive Dentistry, Faculty of Dentistry, College of Health Sciences, University of Port Harcourt, Choba Port Harcourt, \\ Nigeria \\ Email address: \\ omoigberai.braimoh@uniport.edu.ng (Braimoh O. B.), grace.alade@uniport.edu.ng (Alade G. O.) \\ ${ }^{*}$ Corresponding author
}

To cite this article:

Braimoh Omoigberai Bashiru, Alade Grace Oyenashia. Influence of Socio-economic Status on Oral Health Knowledge, Attitude and Behavior of Pensioners in Port Harcourt, Rivers State. International Journal of Dental Medicine. Vol. 3, No. 3, 2017, pp. 11-15.

doi: $10.11648 /$ j.ijdm.20170303.11

Received: June 18, 2017; Accepted: July 3, 2017; Published: September 12, 2017

\begin{abstract}
Background: Socio-economic status plays a role in influencing oral health and oral health related behaviors and problems. The objective of the present study was to determine the influence of educational status and retirement grade level on oral health knowledge attitude and behavior. Methods: The research was analytic descriptive survey in design. A total of 543 old people were selected by systematic random sampling. Data was collected with a self-developed Oral Health Assessment Questionnaire (OHAQ) designed in four sections (A-D) and analyzed using SPSS version 20 (IBM SPSS Armonk, New York). The relationship between variables was established using independent t-test and ANOVA, and significance determined at 0.05 alpha level. Results: Total of 119 (21.9\%), 198 (36.5\%) and $226(41.6 \%)$ had primary, secondary and tertiary education respectively. The pensioners who retired on levels 1-6 were 277 (51\%) and those who retired on levels 7-17 were 266 (49\%). The level of education significant influenced oral health knowledge, attitude and behavior. Retirement grade level significantly influenced oral health behavior and non-significantly influenced oral health knowledge and attitude. Conclusion: The study found out that oral health knowledge, attitude and behavior increased significantly with increasing level of education. There was a significant increase in oral health behavior with increasing retirement grade level and a non-significant increase in oral health attitude and behavior.
\end{abstract}

Keywords: Pensioners, Oral Health Knowledge, Oral Health Attitude, Socio-economic Status

\section{Introduction}

The risk factors common to a number of chronic diseases are also determinants of oral diseases [1-3]. Therefore, one needs to understand the social determinants of health in order to appreciate the determinants of diseases besides the biomedical factors. The social determinants that influence oral diseases include gender, socioeconomic status, ethnicity, race, cultural belief, accessibility and affordability of health services, stress, poverty and deprivation. Socio-economic status (SES) plays a role in influencing oral health and oral health related behaviors and problems [4]. Broadbent et al, reported that SES, oral health behavior and oral health outcomes are correlated [5].
Utilization of dental services according to is an expression of socioeconomic status [6-8]. Utilization of dental services was found to be more dependent on ability to pay $[7,8]$. Furthermore, Individuals with tertiary education utilise dental service more frequently than those with secondary education and those with secondary education than those with primary education [6-8]. Factors such as income and presence of dental insurance are also associated with the number of dental visits among older Americans aged 55-75 years [9] In another study, it was reported that retirement which is usually accompanied by reduced income and dental insurance coverage in developed countries was accompanied by lower 
utilization of dental services [10]. Again, observed relationship between SES and oral hygiene has been reported. Higher social class has better oral hygiene compared to individuals in the lower strata $[11,12]$.

Individuals with lower level of education are reported to have inadequate oral health behavior compared to those with higher level of education [13]. Level of education also influences knowledge and occurrence of oral diseases. Higher level of education is associated with better health knowledge and better overall periodontal conditions [14-16]. Singh et al. reported that oral health knowledge, attitude and behavior improved with increasing level of education [17].

Based on the findings above, SES is a known determinant of oral disease as well as oral health knowledge, attitude and behavior, hence this study was undertaken to investigate the influence of SES on oral health knowledge, attitude and behavior of pensioners. According to Burt and Eklund SES is a measure of educational status, occupation and income [18]. Occupation and income are dependent on each other; ones occupation determines his or her income. The measure of income in the present study was the retirement grade level of the participants. In the Nigerian public service, the level of employment and retirement varies from level 1-17 and the level on which an individual is placed is dependent on educational status. Levels 1-6 (Primary and Secondary) and 7-17 (tertiary education) are recognized as junior and senior staff respectively. The higher the level, the higher the income; hence worker who retired at higher level would earn bigger pension allowance than those that retire at lower level.

The study population for this study are pensioners in Port Harcourt, Rivers State. This group was selected to represent old people in Port Harcourt because they retire at the age 60 years and according to the United Nation Population Division [19], the Nigerian National Population Commission define the elderly in Nigeria as person's age 60 years and over. There is paucity of data on the oral health of this group. A number of researches conducted in Rivers State focused on school children, young adults, adults and hospital based patients. The objective of this research therefore was to find out the influence of educational status and retirement grade level on the oral health knowledge, attitude and behavior of pensioners in Port Harcourt Rivers State, Nigeria. This study would provide baseline data on oral health of pensioners in Port Harcourt and contribute to data available on the elderly in Nigeria and the rest of the word.

\section{Subjects and Methods}

\subsection{Research Design}

The research design employed in this study was analytic descriptive design. Analytic descriptive design is a study design in which the variables being studied for any sample are compared for the various identified strata of the sample through the use of hypotheses [20]. Thus in this study the authors compared the oral health knowledge, attitude and behavior of the pensioners in relation to their educational status and grade level at retirement.

\subsection{Sample and Sampling Technique}

The population of the study were pensioners in Port Harcourt, Rivers State. The group was considered as elderly since it comprised of old people 60 years and above. The sample size (n) was determined according to the formula for sample size determination by Lwanga and Lemeshow [21] given as $n=\frac{z^{2} p q}{d^{2}}$ for population less than 10,000 at $95 \%$ confidence interval, standard normal deviate (z) of 1.96 and degree of accuracy (d) 0.05 . The proportion (p) of elderly with dental caries was $0.305(30.5 \%)$ [22], and the proportion (q) without dental caries was 0.695 (69.5\%). Therefore, the minimum sample size obtained for this study was 325 .

The subjects were selected by systematic random sampling. The selection was done at the Secretariat of the Nigerian Union of Pensioners (NUP) located at the State Civil Service Secretariat in Port Harcourt. Pensioners in Rivers State routinely visit the Secretariat daily and congregate once monthly for their meetings. The register of the pensioners constituted the sampling frame for this study (source: NUP Secretariat) and every second subject was selected from the register. Subjects selected who were not present in a particular visit were contacted through their phone numbers for subsequent visit.

\subsection{Instrument for Data Collection}

Data was collected by the use of questionnaire. The questionnaire was a structured self-developed Oral Health Assessment Questionnaire (OHAQ) designed in four sections (A-D). Section A contained information on sociodemographic data; section $\mathrm{B}, \mathrm{C}$ and $\mathrm{D}$ on oral health knowledge, behavior and attitudes respectively. Section A contained the demographic information (retirement grade level and educational status), section $\mathrm{B}$ and $\mathrm{C}$ contained questions on oral health knowledge and behavior both were assessed on a scale of yes ( 1 point) or no $(0$ point $)$ for positively constructed questions and yes (0 point) or no (1) for negative questions.

The oral health knowledge of the pensioners was assessed using 20 questions. These included questions on the accumulation of plaque on the teeth, meaning of plaque and its effect on dentition and the gum, the cause of tooth decay, purpose of tooth brushing, meaning of gum bleeding and its reasons, methods to prevent gum bleeding, effect of sugar particularly soft/ fizzy drinks on teeth, methods of prevention of tooth decay, methods of prevention of gum disease, effect of fluorides on teeth, effect caries on aesthetics, relationship of gum disease to diabetes, heart disease, low birth weight. The oral health behavior of the participants was assessed using 16 questions. These included questions on frequency and time of tooth brushing, duration of tooth brushing, material used for brushing teeth, reasons for change of tooth brush, materials used for cleaning the teeth other than tooth brush, reasons for visiting a dentist, frequency of 
consumption of sweets, and bad habits like cigarette smoking.

The oral health attitude of the pensioners was contained in section $\mathrm{D}$ and it had 13 questions. These included questions on attitudes towards regular dental visits, cigarette smoking habit, cleaning of teeth without using paste, care of the teeth, bothering about color of teeth, services / care provided by a dentist, as well as attitude towards dental care and body care in general and involvement in the dental treatment. The questions were assessed on a 4 point modified Likert scale of strongly agree (4 points) agree ( 3 points), disagree ( 2 points) and strongly disagree (1 point) for positive questions and strongly agree (1 point), agree ( 2 points), disagree ( 3 points) and strongly disagree (4 points) for negative questions.

\subsection{Validity and Reliability of the Instrument}

Validity is defined as the accuracy, quality and appropriateness of the modalities adopted for finding answers to the research questions [23]. The researcher believes that this research study is accurate and valid due to the fact that procedures adopted for this study are from scientific and peer reviewed sources. The validity was further justified by presenting the data collecting instrument to the second and third author and based on their expert opinion, comments, criticisms and observations the instrument was modified.

The reliability of the instrument was done using pensioners different from those recruited for the study. Twenty of them were selected; the selected pensioners completed the questionnaire and were examined by the researcher. The filling of the questionnaire and examination was repeated after an interval of one week. The reliability of the instrument was determined using the Cronbach alpha and alpha coefficient of 0.82 was obtained. The reliability testing also served as the pilot-test for the data collecting instrument, from the reaction of the participants to the questionnaire, it was evident that they quite understood the question items. There was evidence that some words were not understood under attitude and knowledge section. This were identified and modified according to the level of participants understanding.

\subsection{Procedure for Data Collection}

Five trained research Assistants were used to ensure proper distribution of the questionnaire to the participants. Rapport was established with the pensioners, the researcher and trained research Assistants explained the purpose of the research to the pensioners and highlighted the importance of privacy, confidentiality and consent. Several visits were made to the Secretariat and at each visit questionnaires were distributed to pensioners for completion. Five hundred and forty three (543) copies of the questionnaire were administered to the respondents and all were retrieved. This took a period of two years from April 2015- March 2017. The study was approved by the Research Ethics Committee, University of Port
Harcourt. Pensioners who retired from public service of Rivers State government voluntarily or retired as a result of years of service, who were below the age of 60 years were excluded from the study, since they do not meet the age to be classified as elderly.

\subsection{Procedure for Data Analysis}

The completed copies of the questionnaires were collated, coded and entered into the Statistical Package for Social Sciences (SPSS) spread sheet. The data was subsequently analysed using SPSS version 20 (IBM SPSS Armonk, New York). Descriptive statistics of percentage, mean and standard deviation were used describe the oral health knowledge, attitude and behavior of the subjects. Individual knowledge score varied from 0-20. The behavior score of individual varied from 0-16. Similarly, attitude score for individual varied from 13-52. The mean knowledge, attitude and behavior score was then calculated for educational status and retirement grade level.

Inferential statistics of independent t-test and analysis of variance (ANOVA) was used to test the association between oral health knowledge, attitude and behavior with educational status and retirement grade level. The hypotheses were rejected if the t-calculated and F-calculated values were equal to or greater than their respective t-critical and F-critical values. In addition, the magnitude of association between the independent variable (age) and the dependent variables (knowledge, attitude and behavior) was determine by the correlation ratio (cE). According to Nwankwo, in order to identify the magnitude of a significant relationship or association between variables which level of significance was determine by ANOVA, correlation ratio is applied to the $F$ calculated value [24]. Interpretation of the nature of relationship was done according to Nwana [25]. According to Nwana, 00-0.19 implies "no relationship or very low (weak) relationship", 0.20-0.39 "low (weak) relationship", 0.40-0.69 "moderate relationship", 0.70-0.89 "high (strong) relationship" and 0.90-1.00 "very high (strong) relationship"

\section{Results}

Total of 119 (21.9\%), 198 (36.5\%) and 226 (41.6\%) had primary, secondary and tertiary education respectively. The pensioners who retired on levels 1-6 were 277 (51\%) and those who retired on levels $7-17$ were 266 (49\%). The mean score and standard deviation for knowledge, attitude and behavior according to the retirement grade level of the participants are shown in Table 1. The knowledge score was $11.6 \pm 1.1$ and $12.8 \pm 0.5$, the attitude score was, $26.5 \pm 1.7$ and $28.7 \pm 1.2$ and behavior score was $6.7 \pm 0.8$ and $10.8 \pm 1.5$ for levels $1-6$ and 717 respectively. The knowledge, attitude and behavior score were higher for grade levels 7-17 than levels 1-6 indicating that grade level influenced the oral health knowledge, attitude and behavior of the pensioners and an increase in grade level was associated with increase in oral health knowledge, attitude and behavior. The calculated t-value for knowledge (1.83) and attitude (1.76) in relation to retirement grade level were less 
than the respective critical t-value of 1.965 at degree of freedom of 541 and 0.05 alpha level. This indicated that oral health knowledge and attitude were not significantly influenced by the grade level at retirement and null hypothesis was accepted. Conversely, the calculated t-value for behavior was 4.32; this was greater than the critical t-value of 1.965 at degree of freedom of 541 and 0.05 alpha level. Therefore, oral health behavior of the pensioners was significantly influenced by their grade level at retirement leading to rejection of the null hypothesis (Table 1).

Table 1. $t$-Test of the influence of retirement grade level on knowledge, attitude and behavior of the pensioners.

\begin{tabular}{|c|c|c|c|c|c|c|c|}
\hline \multirow{2}{*}{ Retirement grade level } & \multirow{2}{*}{$\mathbf{N}$} & \multicolumn{2}{|c|}{ Knowledge } & \multicolumn{2}{|c|}{ Attitude } & \multicolumn{2}{|c|}{ Behavior } \\
\hline & & Mean & SD & Mean & SD & Mean & SD \\
\hline Level 1-6 & 277 & 11.6 & 1.1 & 26.5 & 1.7 & 6.7 & 0.8 \\
\hline Level 7-17 & 266 & 12.8 & 0.5 & 28.7 & 1.2 & 10.8 & 1.5 \\
\hline df & & 541 & & 541 & & 541 & \\
\hline $\mathrm{t}$-cal & & 1.83 & & 1.76 & & 4.32 & \\
\hline t-cri & & 1.965 & & 1.965 & & 1.965 & \\
\hline P-value & & 0.1 & & 0.1 & & 0.02 & \\
\hline
\end{tabular}

The mean score and standard deviation for knowledge, attitude and behavior according to educational status of the pensioners are shown in Table 2. While the knowledge score was $8.6 \pm 0.8,11.7 \pm 0.6$ and $16.4 \pm 1.1$ for participants with primary, secondary and tertiary education status respectively, the attitude score was $24.7 \pm 1.3,27.2 \pm 1.5$ and $30.8 \pm 1.7$ for participants with primary, secondary and tertiary education status respectively. The behavior score for participants with primary education was $5.7 \pm 1.0$, secondary education, $8.2 \pm 1.3$ and tertiary education, $12.4 \pm 0.8$. These results showed that there is difference in oral heath knowledge, attitude and behavior with level of education. The calculated F-value for knowledge (4.87), attitude (6.07) and behavior (7.53) in relation to level of education were greater than their respective critical F-value of 3.00 at degrees of freedom (2 and 540) and at 0.05 alpha level. This indicated that educational status significantly influenced knowledge, attitude and behavior of the pensioners. The correlation ratio of the association between educational status and knowledge was 0.37 , between educational status and attitude, 0.32 and between educational status and behavior was 0.58 . This indicated that whereas a low and positive association existed between knowledge, attitude and educational status, a moderate and positive association existed between level of education and oral health behavior among the pensioners.

Table 2. ANOVA Test of the influence of educational status on knowledge, attitude and behavior of the pensioners.

\begin{tabular}{|c|c|c|c|c|c|c|c|}
\hline \multirow{2}{*}{ Educational level } & \multirow{2}{*}{$\mathbf{N}$} & \multicolumn{2}{|c|}{ Knowledge } & \multicolumn{2}{|c|}{ Attitude } & \multicolumn{2}{|c|}{ Behavior } \\
\hline & & Mean & SD & Mean & SD & Mean & SD \\
\hline Primary & 119 & 8.6 & 0.8 & 24.7 & 1.3 & 5.7 & 1.0 \\
\hline Secondary & 198 & 11.7 & 0.6 & 27.5 & 1.5 & 8.2 & 1.3 \\
\hline Tertiary & 226 & 16.4 & 1.1 & 30.8 & 1.7 & 12.4 & 0.8 \\
\hline & & \multicolumn{2}{|c|}{$\mathrm{dfl}=2, \mathrm{df} 2=540$} & \multicolumn{2}{|c|}{$\mathrm{df} 1=2, \mathrm{df} 2=540$} & \multicolumn{2}{|c|}{$\mathrm{df} 1=2, \mathrm{df} 2=540$} \\
\hline F-cal & & \multicolumn{2}{|c|}{4.87} & \multicolumn{2}{|c|}{6.07} & \multicolumn{2}{|c|}{7.53} \\
\hline F-cri & & \multicolumn{2}{|l|}{3.00} & \multicolumn{2}{|l|}{3.00} & \multicolumn{2}{|l|}{3.00} \\
\hline Decision & & \multicolumn{2}{|c|}{ Significant } & \multicolumn{2}{|c|}{ Significant } & \multicolumn{2}{|c|}{ Significant } \\
\hline correlation ratio $(\mathrm{cE})$ & & \multicolumn{2}{|c|}{0.37} & \multicolumn{2}{|c|}{0.32} & \multicolumn{2}{|c|}{0.58} \\
\hline
\end{tabular}

\section{Discussion}

According to Burt and Eklund (2005) socioeconomic status (SES) is a measure of educational status, occupation and income [18]. SES is vital measure in many health studies because it is closely correlated with many health-related characteristics. Attitude toward health are often part of the set values that follow from an individual's prestige in society and may explain some of the observed differences in health between SES groups [18].

Studies have reported that level of education influences knowledge and occurrence of oral diseases [14-16]. Higher level of education is associated with better health knowledge. Al-Sharbatti et al. in a cross-sectional study reported that individuals with lower level of education had inadequate oral health behavior compared to those with higher level of education [13]. Singh et al. evaluated oral health knowledge, attitude and behavior among Indian population. According their findings, it was observed that oral health knowledge, attitude and behavior improved with increasing level of education [17].

The result of this research is in agreement with previous reports on the influence of education on oral health knowledge, attitude and behavior. In the present study, oral health knowledge, attitude and behavior was significantly influenced by level of education. There was low and positive association between educational status and knowledge with correlation ratio (cE) of 0.37 as well as low and positive association between educational status and attitude with correlation ratio $(\mathrm{cE})$ of 0.32 . The correlation ratio between educational status and behavior was 0.58 , indicating 
moderate and positive association between the variables. The positive association suggests that increase in level of education from primary to tertiary level resulted in improved oral health knowledge, attitude and behavior.

The retirement grade level served as a measure of economic status of the pensioners. Although pensioners on grade level 7-17 had higher knowledge, attitude and behavior scores than those on level 1-6, this difference was not significant for knowledge and attitude. However, the oral health behavior of the pensioners was significantly influenced by retirement grade level, indicating that pensioners on grade level 7-17 are more likely to behavior good oral health behavior than those on level 1-6. This is in agreement with other studies which reported that utilization of dental services was found to be more dependent on ability to pay $[7,8]$ and reduced income was accompanied by lower utilization of dental services [10].

\section{Conclusion}

The study found out that whereas educational status significantly and moderately influenced oral health behavior, a low and positive association existed between knowledge and educational status as well as between attitude and educational status. While a significant association existed between retirement grade level and behavior, a nonsignificant association existed between oral health knowledge, attitude and retirement grade level.

\section{References}

[1] Sheiham A. Oral health, general health and quality of life. Bull World Health Org 2005; 83 (9): 644-51.

[2] Sheiham A, Watt R. The common risk factor approach-a rational basis for promoting oral health. Community Dent Oral Epidemiol 2000; 28: 399-406.

[3] Williams DM, Sheiham A, Watt RG. Oral health professionals and social determinants. Bri Dent J 2013; 214 (9): 427-33.

[4] Petersen PE. Global policy for improvement of oral health in the 21 st century-implications to oral health research of World Health Assembly 2007, World Health Organization. Community Dent Oral Epidemiol 2009; 37 (1): 1-8.

[5] Broadbent JM, Thomson WM, Poulton R. Oral health beliefs in adolescence and oral health in young adulthood. J Dent Res 2006; 85 (4): 339-43.

[6] Aikins EA, \&, Braimoh OB. Self-rated oral health status and associated factors in adult population in Port Harcourt Rivers State Nigeria. J Sci 2015; 5 (7): 505-10.

[7] Kadaluru UG, Kempraj VM, Muddaiah P. Utilization of oral health care services among adults attending community outreach programs. Indian J Dent Res 2012; 23: 841-47.
[8] Pavi E, Karampli E, Zavras D, Dardavesis T, \& Kyriopoulos J. Social determinants of dental health services utilisation of Greek adults. Community Dent Health 2010;27: 145-50.

[9] Manski, R., \& Goldfarb M. Dental utilisation for older Americans aged 55-75. Gerodontol 1996; 13 (1): 49-55.

[10] Manski, R. J., Moeller, J., Chen, H., St Clair, P. A., Schimmel, J., Magder, L., \& Pepper, J. V. Dental care utilization and retirement. J Public Health Dent 2010:70 (1), 67-75.

[11] Grants, A. D., \& Stern, I. B. Periodontics in the tradition of Gottlieb and Orban. ( $6^{\text {th }}$ ed.). St. Louis MO, CV Mosby Company. 1988.

[12] Braimoh, O. B., Sofola, O. O., \& Okeigbemen, S. A. Oral hygiene profile of inmates in a correctional home. Annals of Biomedical Sciences 2012; 11 (2): 36-43.

[13] Al-Sharbatti S, Sadek M. Oral Health Knowledge, Attitudes and Behaviors of the elderly in Ajman, UAE. Gulf Med J 2014; 3 (S2): S152-S64.

[14] Horton JE, Sumnicht, RW. Relationship of educational levels to periodontal disease and oral hygiene with variables of age and geographic regions. J Periodontol 1967;38, 335-9.

[15] Horton JE, Sumnicht RW. Relationship of educational levels to periodontal disease and oral hygiene: II. J Periodontol 1968;39, 333-5.

[16] Horton JE, Zimmerman ER, Collings CK. The effect of toothbrushing frequency on periodontal measurements. J Periodontol 1969;40: 14-6.

[17] Singh K, Kochhar S, Mittal V, Agrawal A, Chaudhary H, Anandani C. Oral health: knowledge, attitude and behavior among Indian population. Educ Res 2012; 3 (1): 66-71.

[18] Burt BA, Eklund SA. Dentistry, Dental behavior and the community $\left(6^{\text {th }}\right.$ ed.). Atlanta GA, Elsevier/Saunders. 2005.

[19] United Nation Population Division. World population prospect: The 2002 revision. New York, United Nations. (2003).

[20] Ogomaka PMC. Types of research. In A. J. Isangedighi and P. M. C. Ogomaka (Eds). Educational research method. Owerri, Totan Publishers Limited. 1992.

[21] Lwanga SK, Lemeshow S. Sample size determination in Health studies: A Practical Manual. World Health Organisation, Geneva. 1991.

[22] Esan TA, Oziegbe EO. Oral health status and treatment needs of elderly people in Ile-ife, Nigeria. East Afri J Pub Health 2013; 10 (3): 535-8.

[23] Kumar R. A step by step for beginners. Research methodology ( $3^{\text {rd }}$ ed.) New Delhi, SAGE. 2011.

[24] Nwankwo OC. Practical guide to research writing $5^{\text {th }}$ ed. Choba, Port Harcourt, University of Port Harcourt Press Limited. 2013.

[25] Nwana BG. Introduction to educational research. Ibadan, Heinemann Educational Book Nigeria Limited. (1992). 